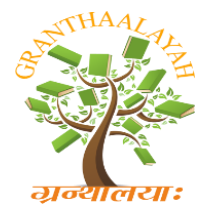

Arts

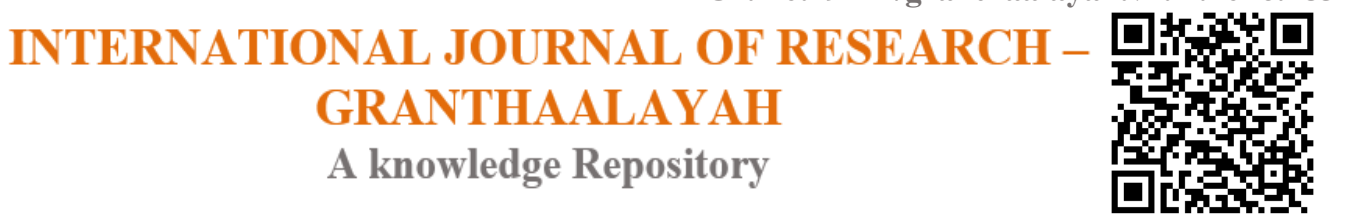

\title{
HEALTH EDUCATION AND COMMUNICATION THROUGH ART
}

\author{
Dr. Anjali Pandey *1 \\ ${ }^{* 1}$ Assistant Professor (Drawing \& Painting), Govt. M.L.B. Girls P.G. College Bhopal, INDIA
}

\begin{abstract}
Health Education promotes the people to adopt the healthy life style. It facilitates the accurate information of medical facilities and new medical discoveries. It motivates the people to resolve problems for themselves and develops the attitude toward health care. The purpose of health education is to transmit the information to the people and encourage them for active involvement in planning and maintenance of their health.
\end{abstract}

Keywords:

Health care system, Health promotion, Community participation, Visual communication, Posters, Puppetry, HEArt'.

Cite This Article: Dr. Anjali Pandey, "HEALTH EDUCATION AND COMMUNICATION THROUGH ART" International Journal of Research - Granthaalayah, Vol. 4, No. 2 (2016): 215219.

\section{INTRODUCTION}

Art serve as a communication channel. It plays vital role in educating the society. It also provides maximum information and proper education with excellent entertainment. It emphasizes the right information of healthy living and outlines the proper usage of medication. Visual helps to communicate more effectively. Posters, slogans, collages, charts are easiest way to educate the people. Puppetry serves as a vehicle of social media. It implants the relevant massage of social awareness easily.

\section{OBJECTIVE OF THE STUDY}

- To raise health awareness, and help them to clarify their values to acquire knowledge,

- To develop attitude toward health care and to increase access to new information and technology of health programs for the people.

- To understand the problems and help people to resolve problems for themselves. 


\section{HEALTH EDUCATION}

Health Education is concerned with establishing changes in personal and group attitudes and behavior that promote healthier living. It is the process of learning by which people learn the maintenance or restoration of health. It is a foundation of preventive health care system. Correct information is the basic part of health education

The World Health Organization defined health education as comprising of consciously constructed opportunities for Learning involving some form of communication design to improve health literacy, including improving knowledge, and developing life skills which are conductive to individual and

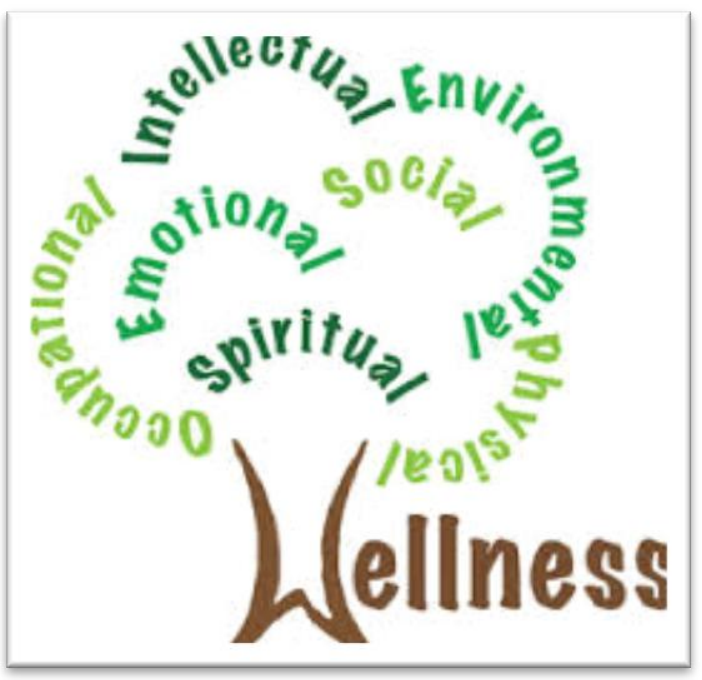
community health."

"Any combination of learning experiences designed to help individuals and communities improve their health, by increasing their knowledge or influencing their attitude." 2 Here the word designed refers the planned activities.

"A process that informs motivates and helps people to adopt and maintain healthy practices and life styles, advocates environmental changes as needed to facilitate the goal and conduct professional training and research to the same end."3

\section{HEALTH EDUCATION THROUGH COMMUNICATION}

According to Aristotle, Speaker Speech and Audience are essential for communication. The main function of communication is to guide or change people's behavior the approach can be influential, entertaining, informative or commanding.4

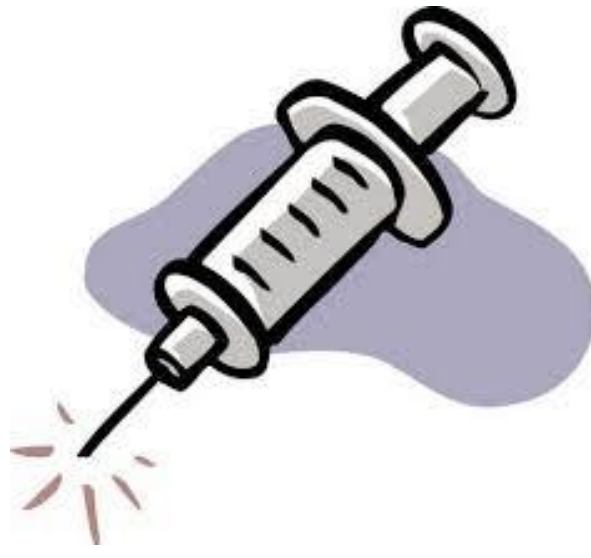

Regarding health education, information, education and communication is necessary. Community participation is necessary for health education. The purpose of health education is to transmit the information to the people and encourage them for active involvement in planning and maintenance of their health.

Communication is a process which informs, motivates, and helps people to adopt and maintain healthy practices by 
using techniques to spread the knowledge on the disease prevention and promotion.5 It prepares people for their expected role. The target group should have the knowledge about disease, its causes, transmission and prevention.

\section{HEALTH MESSAGE AND ROLE OF ART}

Art serve as a communication channel for transmission of knowledge and belief. It plays vital role in educating the society. It helps to increase the knowledge about culture and civilization, values and belief, norms and behavior. It also provides maximum information and proper education with excellent entertainment. It emphasizes the right information of healthy living and outlines the proper usage of medication. "Health for all, all for health" is a massive programme announced by W.H.O. to develop the fine- tune health care system. It should be transmitted through effective and proper way

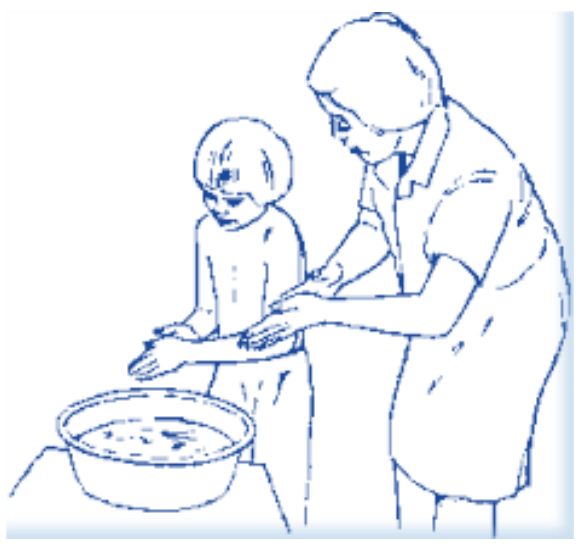
of communication the knowledge regarding various aspect of health should be transmitted to the target user group. 6

People should know what is good for their health. Various researches regarding health should

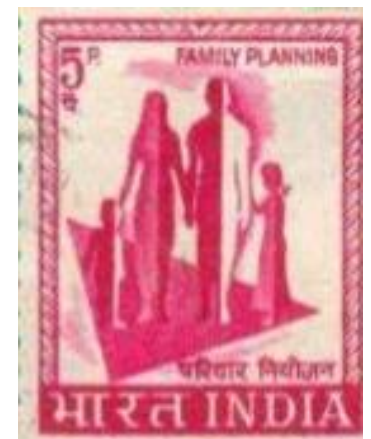
also be focused. The effective communicative programme should organize for awareness of common people. The whole communication process demands the source of communication, audience, message, and medium of communication and the reaction of audience. The types of communication can be one or two way, verbal or non-verbal, formal and informal, visual, telecommunication or internet.

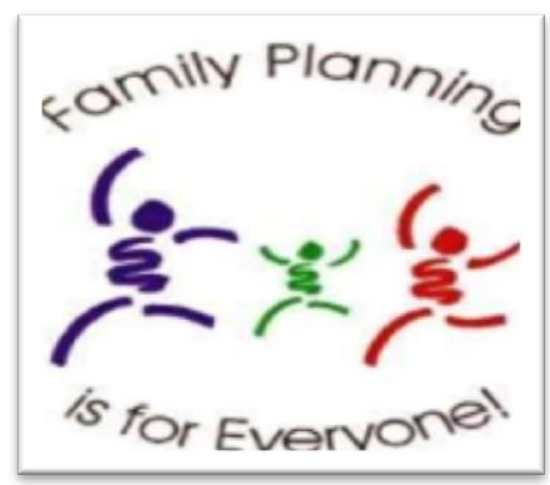

Visual helps to communicate more effectively. It can transmit the message without having the any barrier of language, religion, culture, social and class differences, custom, belief or difficulties in hearing or illiteracy.7

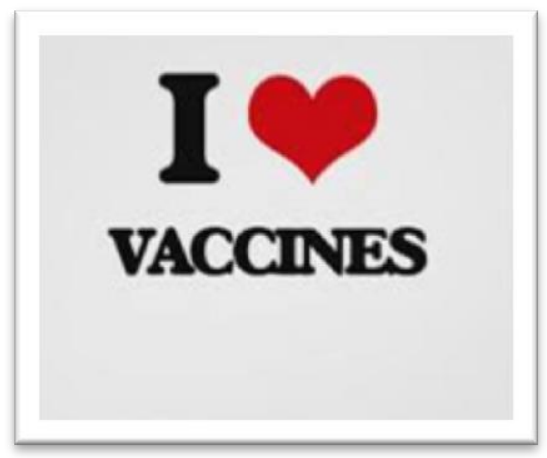

The health education can communicate by individual, group or mass. Traditional and folk art also plays the important role. The aim of the art is to give the right information regarding medication and to promote awareness of healthy living in

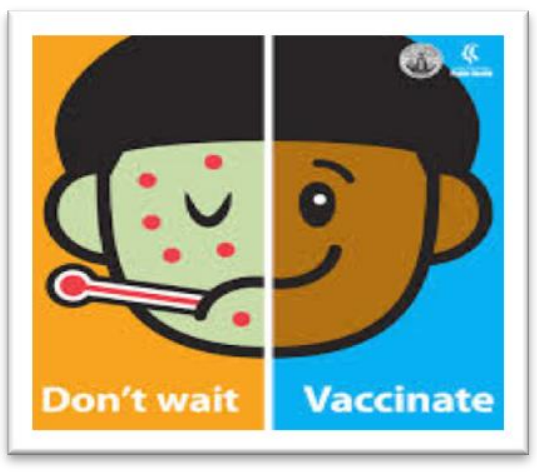


between general public with help of social workers, teachers etc.

Communicator, Message channel and audience are necessary needs for Communication. Clear massage, active listeners and credibility of source needed for good communication. In the communication art plays important role. It acts as a physical bridge between the sender and receiver. In this way the communicator and receiver is the important person. It is a two way

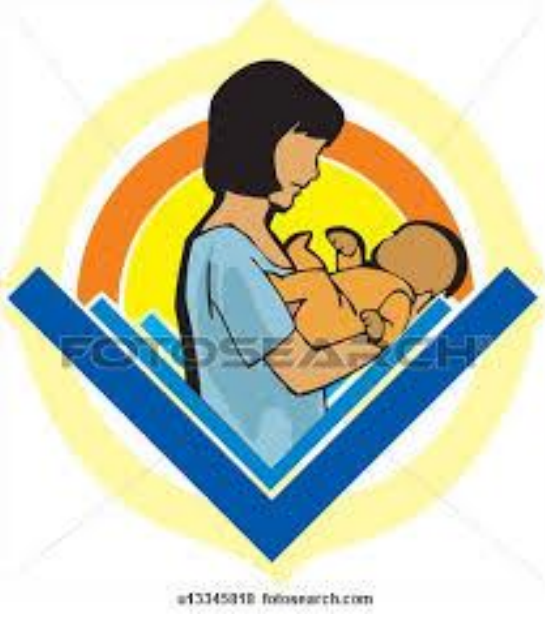
process of exchanging plans, feelings, and information. For good communication massage should be clear and effective and according to the viewers either it is concern with individual, group or mass. 8

Family planning, Hygiene, Mother Childcare, breastfeeding, vaccination control of communicable and non-communicable diseases, and prevention of accidents are the major contents of health education. It provides basic knowledge of health practices, which comes out by the experiences, experiments and tradition. Each culture has its own system and a way of doing. Belief, values, resources and the behavior form the pattern of life. 9

Teaching provides basic knowledge and good practices of health. Health exhibition, posters, slogans, collages, charts are easiest way to educate the people Teaching provides basic knowledge and good practices of health. Films and T.V. theatre and radio, Newspaper and booklets are much more effective.
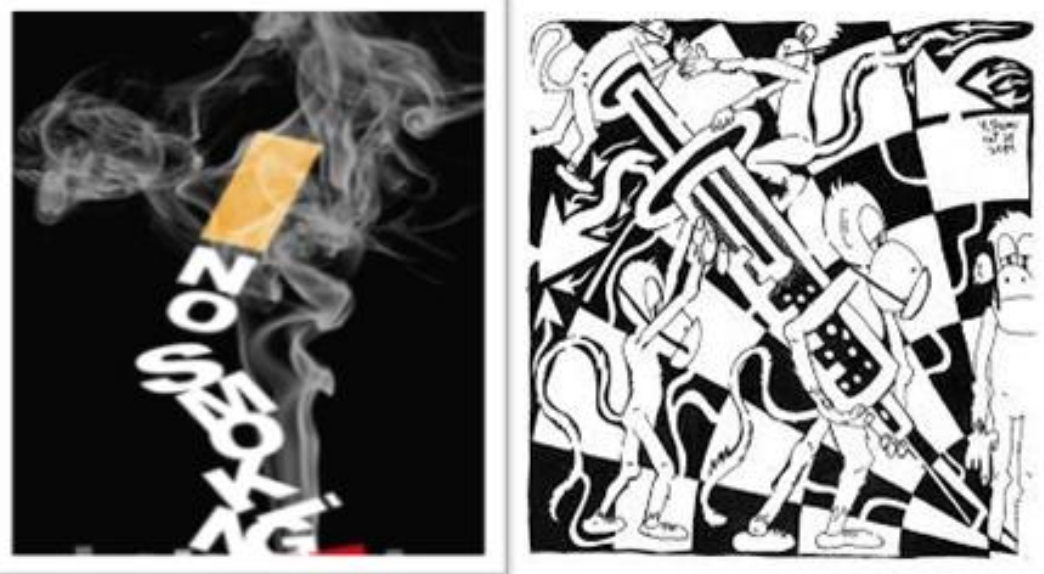

Health promotion, disease prevention and utilization of available sources, all approach to Health promotion should be interesting, participating and motivating. For active involvement method of learning by doing can be apply. 


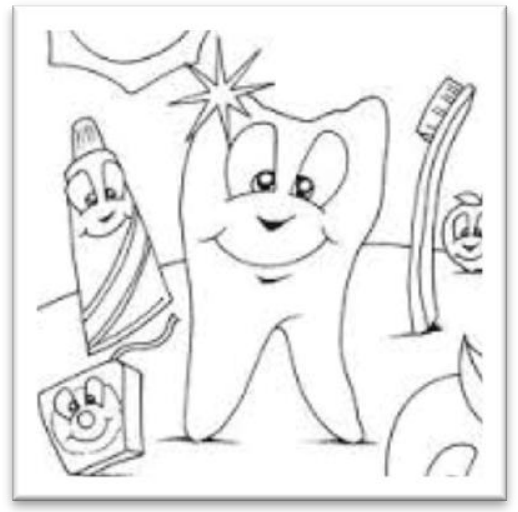

of accidents.

Puppetry is old tradition in India serves as a vehicle of social media. In recent years the use of this tradition is increased in field of communication. It is an interesting way of communication for children as well as general people. The puppet master manipulates the ideas and theme in stylized and comic way. The relevant massage of social awareness can implant easily with the help puppetry. The contents of health education are nutrition, human biology, environmental and personal hygiene, control of communicable family health, mental health, and prevention

Now these days, 'HEArt'( Health education through art) is employing the leadership qualities to face the changes and empower them to make Healthy decisions. The curriculum, of the HEArt is "Healthy life style for Youth', the innovative use of web and video technology for demonstration develops the self-efficiency.
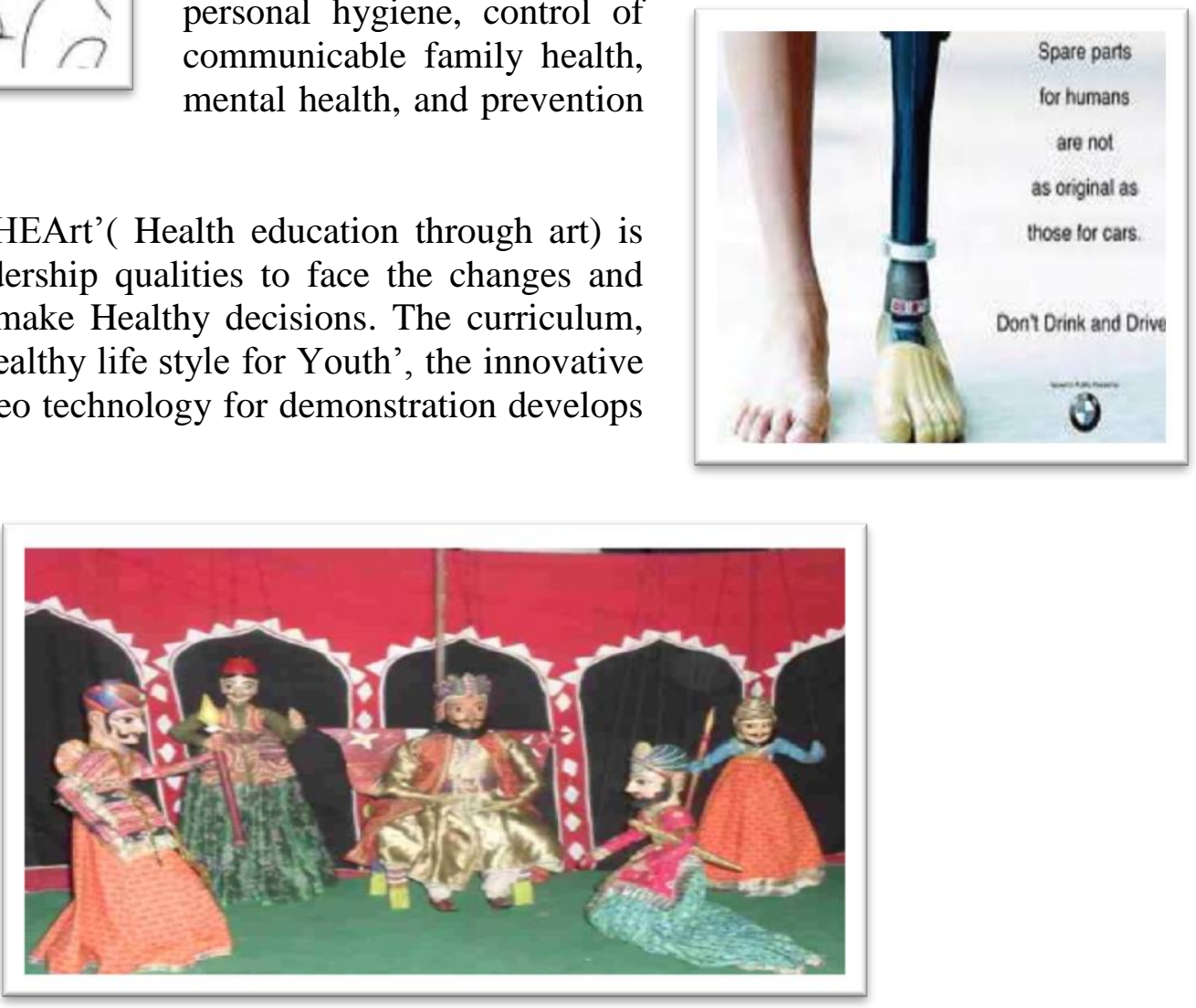

\section{REFERENCES}

[1] Wikipedia.com

[2] www.who.int>topics>health_education

[3] www.drjayeshpatidar.blogspot.com

[4] Mukhopadhyaya D.G: Folk Arts and Social Communication New Delhi 1916 Pg. 14-15).

[5] Mukhopadhyaya D.G: Health Education information and Communication: Pg. 31.

[6] www.drjayeshpatidar.blogspot.com

[7] Mukhopadhyaya D.G ibid Pg -32

[8] Mukhopadhyaya D.G ibid Pg -10

[9] Pandey Anjali, Puppetry: Education through entertainment/International journal of Social and Life Sciences ;Pg-125-129

[10] www.muralmusicarts.org 